\title{
Activin Type 2B Receptor Fc Fusion Protein STM 434
}

National Cancer Institute

\section{Source}

National Cancer Institute. Activin Type 2B Receptor FC Fusion Protein STM 434. NCI

Thesaurus. Code C118625.

A soluble fusion protein containing the extracellular domain of the activin receptor type 2B (ACVR2B or ActRIIB) fused to a human Fc domain, with potential antineoplastic activity. Upon intravenous administration, ST M 434 selectively binds to the growth factor activin A, thereby preventing its binding to and the activation of endogenous ActRIIB. This prevents activin A/ActRIIB-mediated signaling and inhibits the proliferation of activin A-overexpressing tumor cells. Activin A, a member of the transforming growth factor beta (T GF-beta) superfamily, is overexpressed in a variety of cancers and plays a key role in promoting cancer cell proliferation, migration, and survival. 